OPEN

SUBJECT AREAS:

MECHANICAL

PROPERTIES

METALS AND ALLOYS

Received

30 April 2014

Accepted

30 June 2014

Published

21 July 2014

Correspondence and requests for materials should be addressed to

Y.-Y.Z. (zhaoyy@ nimte.ac.cn); B.L.S. (blshen@seu.edu.cn) or R.-W.L. (runweili@ nimte.ac.cn)

\section{Composition Effect on Intrinsic Plasticity or Brittleness in Metallic Glasses}

\author{
Yuan-Yun Zhao ${ }^{1,2}$, Akihisa Inoue ${ }^{1,2,3}$, Chuntao Chang ${ }^{1,2}$, Jian Liu ${ }^{1,2}$, Baolong Shen ${ }^{4}$, Xinmin Wang ${ }^{1,2}$ \\ \& Run-Wei Li',2
}

'Key Laboratory of Magnetic Materials and Devices, Ningbo Institute of Materials Technology and Engineering, Chinese Academy of Sciences, Ningbo 315201 , China, ${ }^{2}$ Zhejiang Province Key Laboratory of Magnetic Materials and Application Technology, Ningbo Institute of Materials Technology and Engineering, Chinese Academy of Sciences, Ningbo 315201, China, ${ }^{3}$ International Institute of Green Materials, Josai International University, Togane 283-8555, Japan, ${ }^{4}$ School of Materials Science and Engineering, Southeast University, Nanjing 211189 , China.

The high plasticity of metallic glasses is highly desirable for a wide range of novel engineering applications. However, the physical origin of the ductile/brittle behaviour of metallic glasses with various compositions and thermal histories has not been fully clarified. Here we have found that metallic glasses with compositions at or near intermetallic compounds, in contrast to the ones at or near eutectics, are extremely ductile and also insensitive to annealing-induced embrittlement. We have also proposed a close correlation between the element distribution features and the plasticity of metallic glasses by tracing the evolutions of the element distribution rearrangement and the corresponding potential energy change within the sliding shear band. These novel results provide useful and universal guidelines to search for new ductile metallic glasses at or near the intermetallic compound compositions in a number of glass-forming alloy systems.

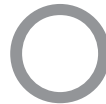

ver the last two decades, bulk metallic glasses (BMGs), which exhibit favourable mechanical properties, have attracted significant attention as novel structural materials because they possess many advantages in terms of engineering applications, such as outstanding high yield and fracture strength, large elastic strain, high stored energy up to final failure, excellent corrosion resistance and good wear resistance ${ }^{1}$. However, most monolithic BMGs usually exhibit catastrophic failure during room temperature deformation due to highly localized shear bands, which significantly limits the possible applications fields of $\mathrm{BMGs}^{1-3}$. Therefore, obtaining monolithic BMGs with high plasticity and understanding the reason why some metallic glasses are brittle whereas others are relatively ductile are of great importance from both scientific and engineering perspectives. In the past decade, it has been reported that monolithic BMGs with various alloy compositions exhibit a significant diversity in the fracture toughness and/or plasticity ${ }^{4-8}$, which has been interpreted to be associated with the critical values for elastic and shear moduli, e.g., Poisson's ratio $(v)^{5,8-9}$. For example, BMGs with high $v$ values above $0.31-0.32$ that contain $\mathrm{Pd}, \mathrm{Pt}, \mathrm{Cu}$, and $\mathrm{Zr}$ as base components are relatively tough, whereas $\mathrm{Mg}$ - and $\mathrm{Fe}$-based systems with low $v$ values less than $0.31-0.32$ are brittle . Although this empirical rule has led to the successful designing of BMGs with high plasticity by alloying with elements possessing high $v$ value ${ }^{5,10}$, one can notice the significant disparity in the empirical rule of toughness/plasticity among major BMGs. For example, some Au- and Pd-based BMGs possess high $v$ values exceeding 0.39 , but they clearly demonstrate a brittle behaviour ${ }^{7,11}$. Thus, the mechanism and origin for the formation of ductile BMGs are not fully understood. In addition, when metallic glasses are annealed at a temperature below and near glass transition temperature $\left(T_{\mathrm{g}}\right)$, the structure relaxes towards a lower internal energy state. This phenomenon is known as structural relaxation and is usually accompanied by severe annealing-induced embrittlement for most of metallic glasses ${ }^{3,12,13}$. The embrittlement of annealed metallic glasses has mainly been attributed to a reduction in free volume, $v_{\mathrm{f}}$, which is defined as the portion of volume surrounding an atom that can be exchanged with neighbouring atoms without requiring any energy expenditure ${ }^{12,14}$. However, in view that the validity of the free-volume concept is obvious for systems of hard-spheres, the relevance of the concept is less obvious in understanding the ductile-to-brittle transition of the relaxed metallic glasses. Since atoms are soft and squeezable they may be able to move without free space ${ }^{15}$. Therefore, the physical origin of the ductile/brittle behaviour of metallic glasses with wide ranges of alloy compositions and thermal histories has not been fully clarified.

It is well known that a eutectic alloy system is preferable for the formation of bulk metallic glass by cooling a liquid with a composition at or near its eutectic composition ${ }^{16}$. However, bulk glass formation is also singularly 

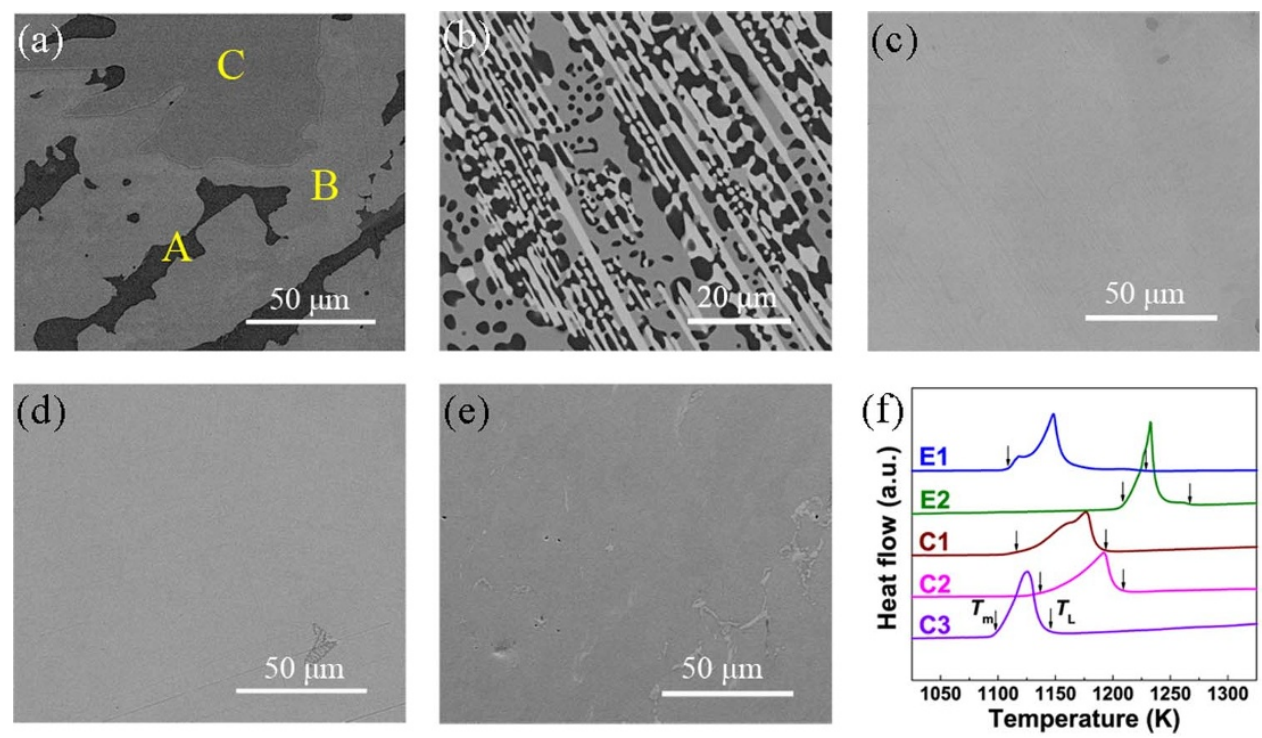

Figure 1 | Composition characteristics. (a-e) Near-equilibrium solidification microstructures of the E1, E2, C1, C2, and C3 alloys quenched at 1023 K, respectively. The C1, C2, and C3 alloys are located at or very close to each intermetallic compound composition. (f) The DSC traces of the E1, E2, C1, C2, and $\mathrm{C} 3$ alloys near their melting temperatures during heating.

observed for a few alloys with intermetallic compound compositions ${ }^{17,18}$. For example, a $\mathrm{Cu}_{50} \mathrm{Zr}_{50}$ BMG can be formed precisely at the composition of CuZr intermetallic compound ${ }^{18}$. Unfortunately, due to the lack of an intensive study of bulk metallic glasses located at or near intermetallic compound compositions (C-MGs), C-MGs are seldom found and few systematic studies have been performed on the differences in structure, thermal stability, deformation and ductility between C-MGs and metallic glasses located at or near eutectic compositions (E-MGs).

Here we have found that the dramatic composition effect on ductile/brittle behaviour of metallic glasses in different thermal history states can be well understood by the new concept of E-MGs and CMGs classification. We clarified systematically for the first time that the E-MGs in the as-cast state are brittle, whereas the C-MGs are ductile. Although the progress of structural relaxation by annealing causes an increase in yield strength, hardness and density for both the E-MGs and the C-MGs, its influence on plasticity is dependent on the types of metallic glass. Specifically, the limited plasticity of the EMG alloys corresponding to a number of bulk glassy alloys decreases further with annealing, whereas the high plasticity of the C-MG alloys is preserved. Moreover, we have also revealed a close correlation between the element distribution characteristics and the plasticity of metallic glasses on the basis of the evolutions of the differences in the element distribution state and the corresponding potential energy change within the sliding shear band. In addition, the element distribution features of typical E-MG and C-MG have also been experimentally proved to be inhomogeneous and homogeneous, respectively.

\section{Results}

Composition features of the E-MGs and C-MGs. We chose $\mathrm{Cu}_{60^{-}}$ $\mathrm{Zr}_{30} \mathrm{Ti}_{10}, \mathrm{Cu}_{49} \mathrm{Hf}_{42} \mathrm{Al}_{9}, \mathrm{Cu}_{47} \mathrm{Zr}_{47} \mathrm{Ti}_{6}, \mathrm{Cu}_{44} \mathrm{Zr}_{52} \mathrm{Al}_{4}$, and $\mathrm{Zr}_{58} \mathrm{Cu}_{15^{-}}$ $\mathrm{Ni}_{15} \mathrm{Al}_{12}$ bulk glass-forming alloys, which are labelled with $\mathrm{E} 1, \mathrm{E} 2$, $\mathrm{C} 1, \mathrm{C} 2$, and $\mathrm{C} 3$, respectively. Figure 1a-e show the representative near-equilibrium solidification microstructures of the E1, E2, C1, C2, and C3 alloys, respectively. The near-equilibrium solidification microstructure of the E1 alloy includes three crystalline phases, marked with $\mathrm{A}, \mathrm{B}$, and $\mathrm{C}$, with nominal compositions of $\mathrm{Cu}_{48} \mathrm{Zr}_{32} \mathrm{Ti}_{20}$ (the $\mathrm{Cu}_{2} \mathrm{ZrTi}$ phase), $\mathrm{Cu}_{57} \mathrm{Zr}_{37} \mathrm{Ti}_{6}$ (the $\mathrm{Cu}_{10} \mathrm{Zr}_{7}$ phase with $\mathrm{Ti}$ solution), and $\mathrm{Cu}_{74} \mathrm{Zr}_{25.5} \mathrm{Ti}_{0.5}$ (the $\mathrm{Cu}_{8} \mathrm{Zr}_{3}$ phase), respectively ${ }^{19}$. In the E2 alloy, a typical ternary eutectic structure can be observed. The white-, black-, and gray-colored phases in the eutectic structure have a composition of $\mathrm{Cu}_{35} \mathrm{Hf}_{65}$ (the $\mathrm{CuHf}_{2}$ phase), $\mathrm{Cu}_{56} \mathrm{Hf}_{23} \mathrm{Al}_{21}$ (the $\mathrm{Cu}_{11} \mathrm{Hf}_{4} \mathrm{Al}_{5}$ phase), and $\mathrm{Cu}_{59} \mathrm{Hf}_{41}$ (the $\mathrm{Cu}_{10} \mathrm{Hf}_{7}$ phase), respectively. Thus the E1 and E2 alloys with eutectic reactions of $L \rightarrow \mathrm{Cu}_{10} \mathrm{Zr}_{7}+\mathrm{Cu}_{8} \mathrm{Zr}_{3}+\mathrm{Cu}_{2} \mathrm{ZrTi}^{19}$ and $L \rightarrow$ $\mathrm{Cu}_{10} \mathrm{Hf}_{7}+\mathrm{CuHf}_{2}+\mathrm{Cu}_{11} \mathrm{Hf}_{4} \mathrm{Al}_{5}{ }^{20,21}$, respectively, are represented as E-MGs. On the other hand, the near-equilibrium solidification microstructures of the $\mathrm{C} 1, \mathrm{C} 2$, and $\mathrm{C} 3$ alloys consist of a mostly single phase with the same composition as the alloys (although a small amount of second phase is observed), indicating that the $\mathrm{C}$, $\mathrm{C} 2$, and $\mathrm{C} 3$ alloys are located at or very close to each intermetallic compound composition. Thus the $\mathrm{C} 1, \mathrm{C} 2$, and $\mathrm{C} 3 \mathrm{BMGs}$ are represented as C-MGs. Figure 1f shows the DSC traces of the E1, $\mathrm{E} 2, \mathrm{C} 1, \mathrm{C} 2$, and $\mathrm{C} 3$ alloys in the temperature range near their melting temperatures during heating. The onset temperature of melting $\left(T_{\mathrm{m}}\right)$ and liquidus temperature $\left(T_{\mathrm{L}}\right)$ are summarized in Table 1 . The dominative single endothermic signals further prove that the compositions of these alloys are located at or very close to the eutectic compositions (E1 and E2 alloys) or the intermetallic compound compositions(C1, C2, and C3 alloys).

XRD and DSC. Figure 2a shows the XRD patterns of the E1, E2, C1, C2, and C3 rod samples with a diameter of $2.5 \mathrm{~mm}$ prepared by copper mould casting. These samples were annealed for $3 \mathrm{~h}$ at $T_{\mathrm{g}}$ $20 \mathrm{~K}$. No distinct peak corresponding to crystalline phase is observed in the diffraction patterns of the annealed samples, indicating that all of these alloys have a glass-forming ability with maximum diameters above $2.5 \mathrm{~mm}$ and that the well-annealed samples are structurally relaxed in the absence of crystalline phases. The glassy nature of the $2.5 \mathrm{~mm}$ rod samples is further ascertained from optical micrographs (see Supplementary Fig. S1). The $T_{\mathrm{g}}$ of the as-cast E1, E2, C1, C2, and C3 BMGs is $705 \mathrm{~K}, 776 \mathrm{~K}, 659 \mathrm{~K}, 678 \mathrm{~K}$, and $683 \mathrm{~K}$, respectively (Fig. 2b). After annealing for $3 \mathrm{~h}$ at $T_{\mathrm{g}}-20 \mathrm{~K}$, these samples show a much clearer endothermic heat recovery in the glass transition region as compared with the as-cast samples (Fig. 2c).

Deformation behaviour in compressive and bending tests. Figure $3 \mathrm{a}$ and $\mathrm{b}$ show the stress-displacement curves of the as-cast and annealed E1, E2, C1, C2, and C3 BMGs, respectively. The as-cast E1, E2, C1, C2, and C3 BMGs exhibit elastic strain limits of $\sim 2 \%$ 
Table 1 The mechanical properties, the glass transition temperatures $\left(T_{\mathrm{g}}\right)$, the onset temperature of melting $\left(T_{\mathrm{m}}\right)$, the liquidus temperature $\left(T_{L}\right)$, and the density changes by annealing (or free volume changes by annealing, $\left.\Delta v_{f}=\left(\Delta V / V_{0}\right) \times 100 \%\right)$ of the E $1, E 2, C 1, C 2$, and C3 BMGs investigated in the as-cast and annealed states

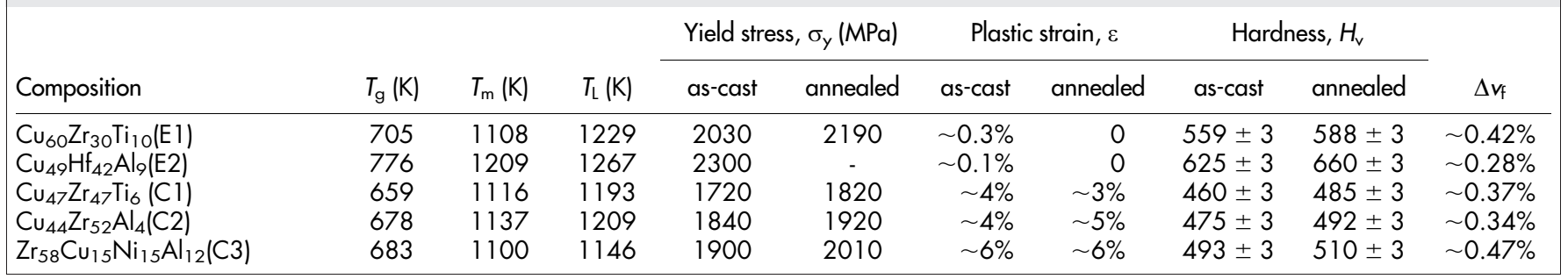

before yielding at $\sim 2030, \sim 2300, \sim 1720, \sim 1840$, and $\sim 1900 \mathrm{MPa}$ with plastic displacements of $\sim 0.01, \sim 0.004, \sim 0.15, \sim 0.15$, and $\sim 0.23 \mathrm{~mm}$, respectively (Fig. 3a). These displacements correspond to nominal engineering plastic strains of $\sim 0.3 \%, \sim 0.1 \%, \sim 4 \%, \sim 4 \%$, and $\sim 6 \%$, respectively. As shown in Fig. $3 \mathrm{~b}$, the yield stress value of the annealed $\mathrm{E} 1 \mathrm{BMG}$ is $\sim 2190 \mathrm{MPa}, \sim 8 \%$ higher than that of the as-cast sample. However, no plastic strain can be observed for the annealed E1 sample. As for the annealed E2 BMG, the test sample fails at a stress $\left(\sigma_{\mathrm{f}}=2060 \mathrm{MPa}\right)$ far before yielding, exhibiting an obviously brittle behaviour. On the other hand, the yield stress values of the annealed C1, C2, and C3 BMGs are $\sim 1820, \sim 1920$, and $\sim 2010 \mathrm{MPa}$, respectively, which are $\sim 5-6 \%$ higher than those of the as-cast samples. Especially, it is notable that the plastic displacements of the annealed $\mathrm{C} 1, \mathrm{C} 2$, and $\mathrm{C} 3 \mathrm{BMGs}$ are very similar to those obtained for the as-cast $\mathrm{C} 1, \mathrm{C} 2$, and $\mathrm{C} 3 \mathrm{BMG}$ samples, with nominal engineering plastic strains of $\sim 3 \%, \sim 5 \%$, and $\sim 6 \%$, respectively.

Table 1 summarizes the mechanical properties and the annealinginduced density change (or annealing-induced free volume change, $\left.\Delta v_{\mathrm{f}}=\left(\Delta \mathrm{V} / \mathrm{V}_{0}\right) \times 100 \%\right)$ of the E1, E2, C1, C2, and C3 BMGs. The $\Delta v_{\mathrm{f}}$ values are measured to be $0.42 \%, 0.28 \%, 0.37 \%, 0.34 \%$, and $0.47 \%$ for the E1, E2, C1, C2, and C3 BMGs, respectively. This clearly indicates that the reductions in $\Delta v_{\mathrm{f}}$ by annealing are not related to the ductile/brittle behaviour of metallic glasses, being inconsistent with the previous common concepts.

The inset in Fig. $3 \mathrm{~b}$ shows that a dominative single shear band contributes to most of the plastic deformation of the C3 BMG sample. With the aim of further confirming the significant difference in the deformability between E-MGs and C-MGs in the as-cast and annealed states, bending tests are also performed. The outer appearances of the bent specimens are presented in Fig. 3c. The as-cast E1 and E2 plate samples show limited bending deformation prior to failure, and their deformability is apparently reduced by annealing. On the other hand, marked deformability and multiple shear bands are observed on the compression and tensile stress sides of the $\mathrm{C}$, $\mathrm{C} 2$, and $\mathrm{C} 3$ plate samples in both the as-cast and annealed states after they were bent over a pressure head with a mandrel radius of $5 \mathrm{~mm}$ (Fig. $3 c-e)$.The results of the compressive and bending tests clearly indicate that the E-MGs in the as-cast state are brittle, whereas the CMGs are ductile. In addition, although structural relaxation by annealing causes an increase in yield strength, hardness and density for both the E-MGs and the C-MGs, its influence on plasticity is dependent on the types of bulk metallic glass. The limited plasticity of the E-MG samples decreases further with annealing, whereas the high plasticity of the C-MG samples is preserved.

A deformation model. According to the potential energy landscape theory $^{22}$, different atomic configurations of metallic glasses are located in distinct energy minimum states ${ }^{23,24}$. Structural relaxation or shear flow of metallic glasses can be described as an activated transition between neighbouring energy minimum states by surmounting an energy barrier ${ }^{25,26}$. The extra energy that is provided to the system, either by annealing or stress, assists this transition $^{27}$. The local minima, and therefore the energy barriers, may eventually disappear with increasing annealing time or stress. This process renders the system mechanically unstable and forces the (a)

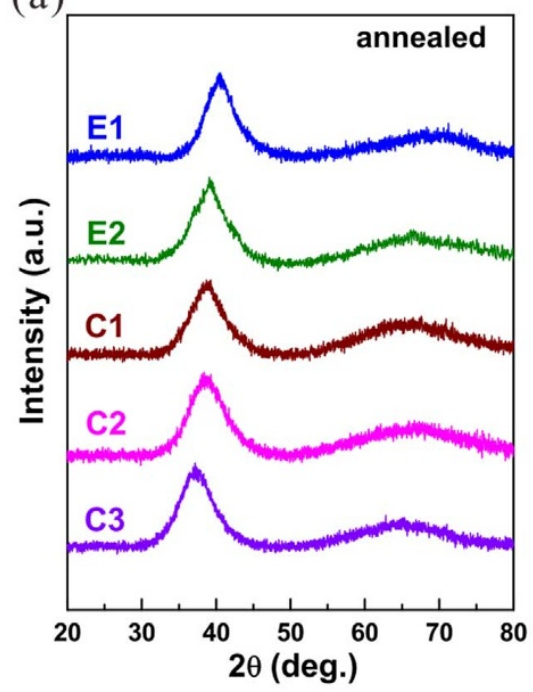

(b)

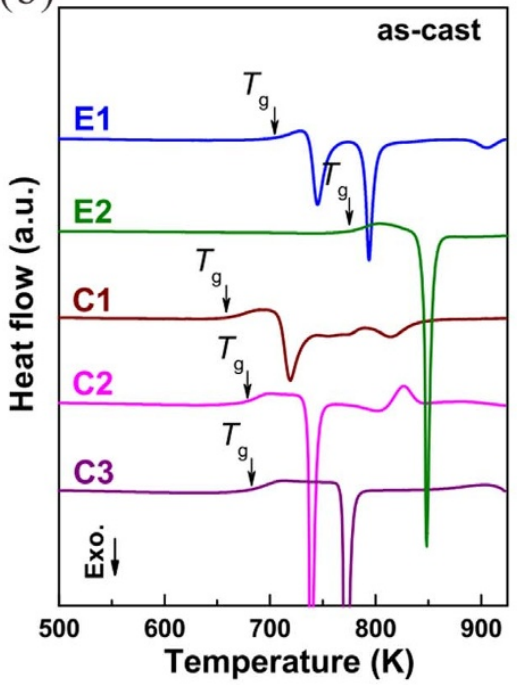

(c)

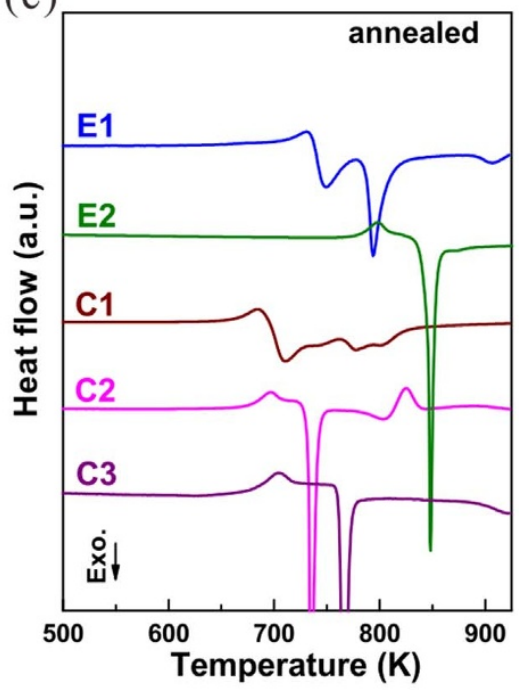

Figure $2 \mid$ XRD patterns and DSC traces. (a) XRD patterns of the E1, E2, C1, C2, and C3 BMG rods with a diameter of 2.5 mm prepared by copper mould casting. The samples were annealed for $3 \mathrm{~h}$ at $T_{\mathrm{g}}-20 \mathrm{~K}$. (b) and (c) DSC traces of the as-cast and annealed E1, E2, C1, C2, and C3 BMG rods with a diameter of $2.5 \mathrm{~mm}$, respectively. 
(a)

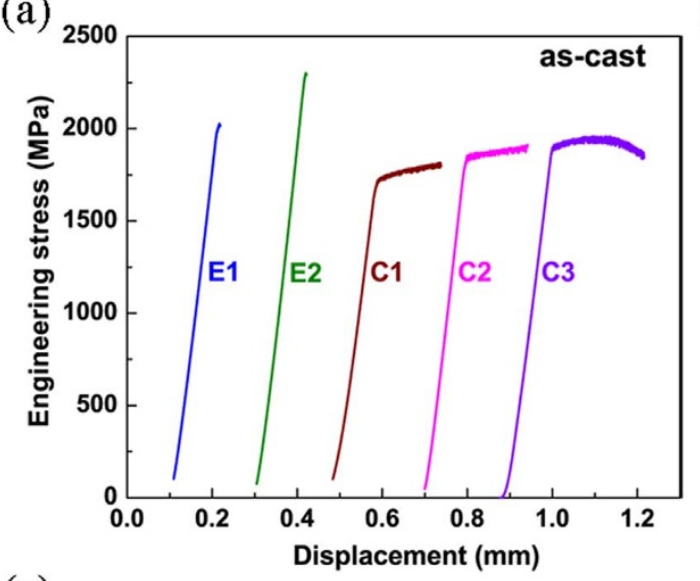

(c)

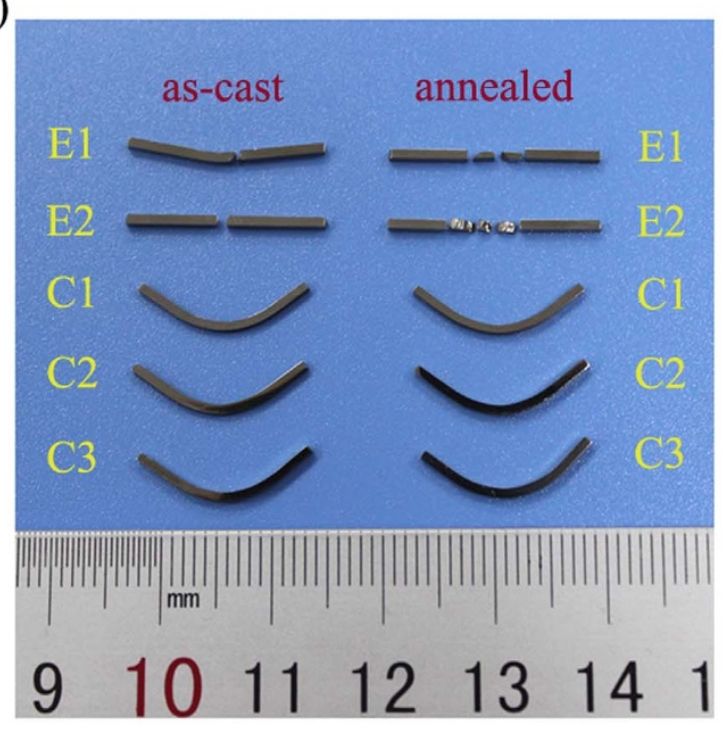

(b)

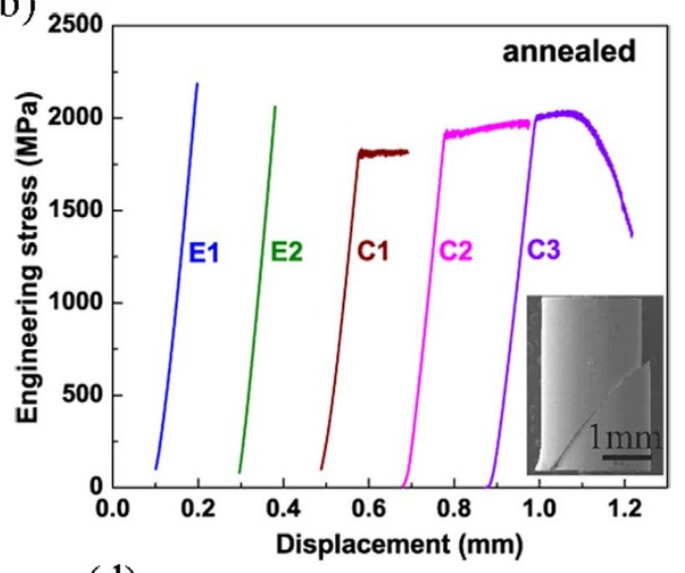

(d)

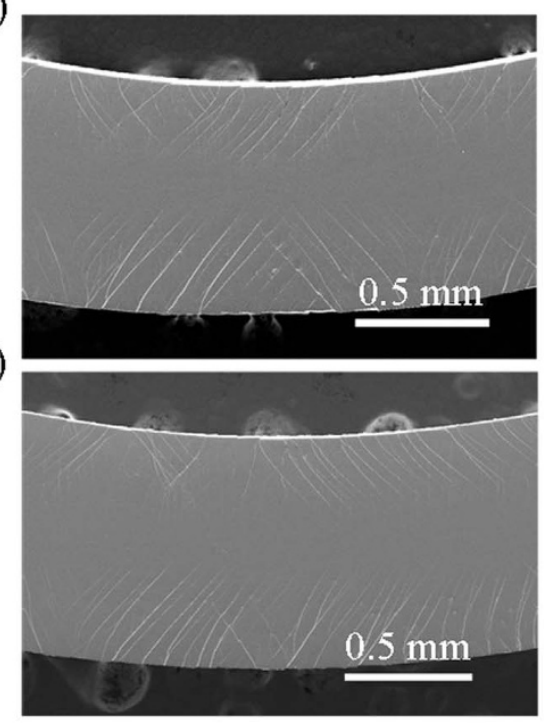

Figure $3 \mid$ Deformation behaviours in compressive and bending tests. (a) and (b) Compressive stress-displacement curves of the as-cast and annealed E1, E2, C1, C2, and C3 BMG rods with a diameter of $2 \mathrm{~mm}$, respectively. The inset of (b) shows that the deformation of the annealed C3 BMG was concentrated within a single dominative shear band. (c) Pictures of the outside of the as-cast and annealed E1, E2, C1, C2, and C3 plate samples bent over a mandrel with a $5 \mathrm{~mm}$ radius. (d) and (e) SEM micrographs of the as-cast and annealed C3 BMG plate samples after bending, respectively.

transition of the metallic glass to a different atomic configuration with minimum energy ${ }^{23,28}$. This mechanism is associated with the local atomic configuration of the metallic glasses ${ }^{3,26}$. Therefore, metallic glasses possessing particular element distribution characteristics (inhomogeneous or homogeneous) reflect specific potential energies, which depend on different composition characteristics and thermal histories. Based on the potential energy landscape theory and the present experimental results, a close correlation between the element distribution characteristics and the plasticity of metallic glasses can be proposed as follows.

As is well known, when a eutectic liquid is rapidly cooled below its equilibrium melting temperature, there is a driving force for atomic rearrangement and/or element diffusion prior to nucleation, because the free energy of liquid is higher than that of solid phase. Therefore, "up-hill" diffusion takes place until the equilibrium compositions are reached. This process is referred to as spinodal decomposition ${ }^{29,30}$. Based on this kind of atomic rearrangement or partial diffusion process in the supercooled liquid prior to the glass transition in glass-forming alloys ${ }^{31-38}$, Figure $4 \mathrm{a}$ shows a schematic diagram of the element distribution state of an as-cast E-MG, which is related to a binary eutectic transition of $L \rightarrow \alpha+\beta$. The blue- and redcolored atoms represent elements A and B, respectively. Specifically, the composition cluster enriched with either element A or element B has a composition between $L$ and $\alpha$ or $L$ and $\beta$, respectively, which is represented by $\alpha_{1}$ or $\beta_{1}$, respectively. For metallic glasses with this element distribution state, the potential energy related to the chemical configuration is defined as $U_{1}$ (Fig. 4e). When the as-cast E-MG is subjected to isothermal annealing for a sufficiently long time at a temperature close to $T_{\mathrm{g}}$, the additional energy assists the system in surmounting the energy barrier and promotes the diffusion of the elements. When this happens, the composition clusters combine and grow. The grown composition clusters are represented as $\alpha_{2}$ and $\beta_{2}$, which have compositions that are much closer to $\alpha$ and $\beta$ than $\alpha_{1}$ and $\beta_{1}$, respectively (Fig. 4 b). In this element distribution state, the potential energy is defined as $U_{2}$, which, when considering the thermodynamics, is lower than $U_{1}$.

When the as-cast E-MG is subjected to a stress up to the yield strength under a uniaxial compressive stress (as shown in Fig 4d), a single dominating shear band is formed, and viscous flow occurs throughout the entire shear band in a serrated flow manner ${ }^{39}$. The shear band is approximately $10-20 \mathrm{~nm}$ thick ${ }^{40}$, whereas the shear displacement for one sliding event has been measured to be 1$2 \mu \mathrm{m}$ in 1-2 $\mathrm{ms}^{39,41}$. As a result, the local strain in the sliding shear band could increase up to $\sim 100$ in 1-2 ms. Taking into account this extremely large shear strain and the low viscosity due to stressinduced glass transition in the sliding shear band ${ }^{42,43}$, we speculate that the element distribution state over the entire sliding shear band may experience an intense atom mixing effect immediately after 
(a)

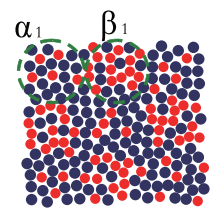

as-cast

(d)

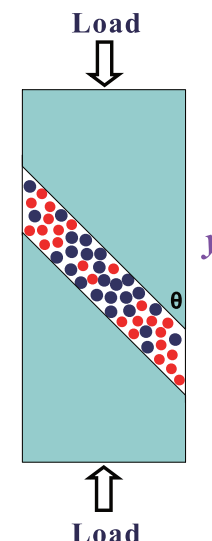

Inhomogeneous (c)

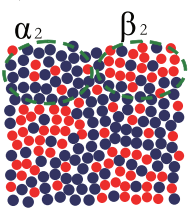

annealed

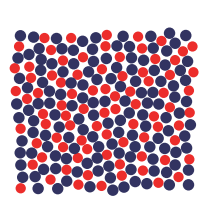

sheared (f)

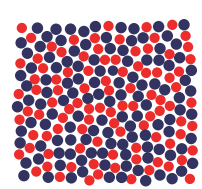

as-cast (g)

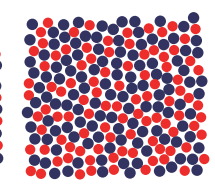

annealed (h)

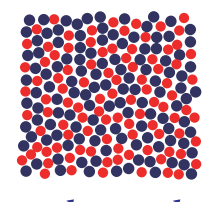

sheared (e)

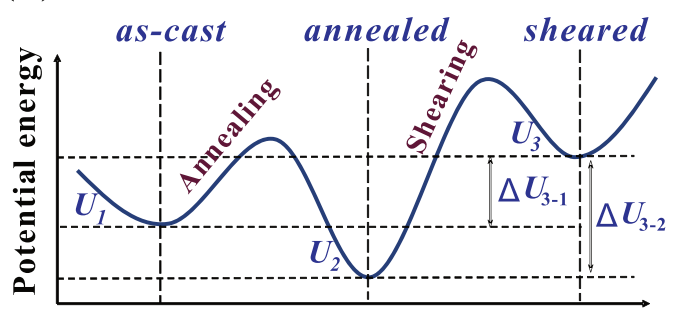

Transition coordinate (i)

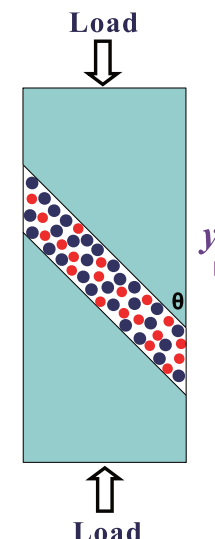

Homogeneous

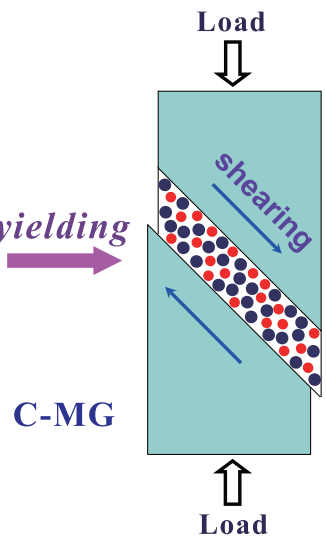

Homogeneous

(j)

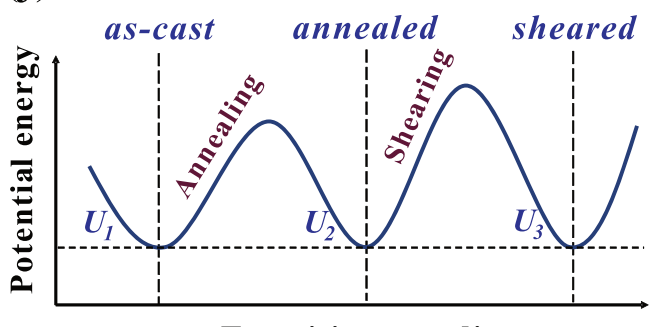

Transition coordinate

Figure 4 | Schematic diagrams of a deformation model of metallic glasses with different composition characteristics and thermal histories. (a), (b) and (c) The element distribution characteristics of an E-MG in as-cast, annealed and sheared state, respectively. (d) The evolution of the element distribution state within the sliding shear band immediately after yielding for the E-MG. The element distribution of the E-MG is inhomogeneous in the as-cast state. This type of inhomogeneous state can be further promoted by structural relaxation, whereas the element distribution state can achieve a completely homogeneous state by an intense mixing effect within the sliding shear band. (e) The corresponding potential energy of the E-MG in different states. The more uniform the element distribution is, the higher the potential energy becomes. (f), (g) and (h) The element distribution characteristics of a C-MG in as-cast, annealed and sheared state, respectively. (i) The evolution of the element distribution state within the sliding shear band after yielding for the CMG. (j) The corresponding potential energy of the C-MG in different states.

yielding. As the sliding distance increases, the mixing effect strengthens. Eventually, a completely homogeneous element distribution state is achieved within a short sliding distance (Fig. $4 \mathrm{c}$ and d). This element distribution state corresponds to a potential energy of $U_{3}$, which, when considering the thermodynamics, is considerably higher than $U_{1}$ and $U_{2}$ (Fig. 4e). Thus, the potential energy of the ascast E-MG within the sliding shear band rapidly increases from $U_{1}$ to $U_{3}$ within a short sliding distance immediately after yielding. The increased potential energy, $\Delta U_{3-1}$, causes an abrupt decrease in atomic bond force and stability within the sliding shear band, resulting in catastrophic failure for the tested samples. Moreover, since the potential energy of the annealed E-MG $\left(U_{2}\right)$ is lower than $U_{1}$, the magnitude of the increased potential energy within the sliding shear band $\left(\Delta U_{3-2}\right)$ is lager than $\Delta U_{3-1}$. This result means that a larger reduction in atomic bond force and stability occurs for the annealed sample than that for the as-cast one. Therefore, the annealed E-MG is much more brittle than the corresponding as-cast E-MG.
On the other hand, since the competitive crystalline phase of a CMG has the same composition as the alloy, chemical decomposition does not occur in the supercooled liquid phase prior to the glass transition and a homogeneous distribution of the constituent elements is expected in the frozen metallic glass phase. Thus the chemical distribution of the C-MG in the as-cast or annealed states is identical to the chemical distribution in the sliding (completely mixed) state immediately after yielding (Fig. 4f-i). Accordingly, the potential energies in different states are equal, that is, $U_{3}=U_{1}$ or $U_{3}=U_{2}$ (Fig. $4 \mathrm{i}$ and $\mathrm{j}$ ). The uniformity of the potential energy within the sliding shear band before and after yielding allows a stable propagation of the sliding shear band. Therefore the C-MG is highly ductile in both the as-cast and annealed states.

Element distribution investigation. With the aim of confirming the appropriateness of the above model, we investigate the element distribution states of the as-cast and annealed E1 and C1 BMGs 

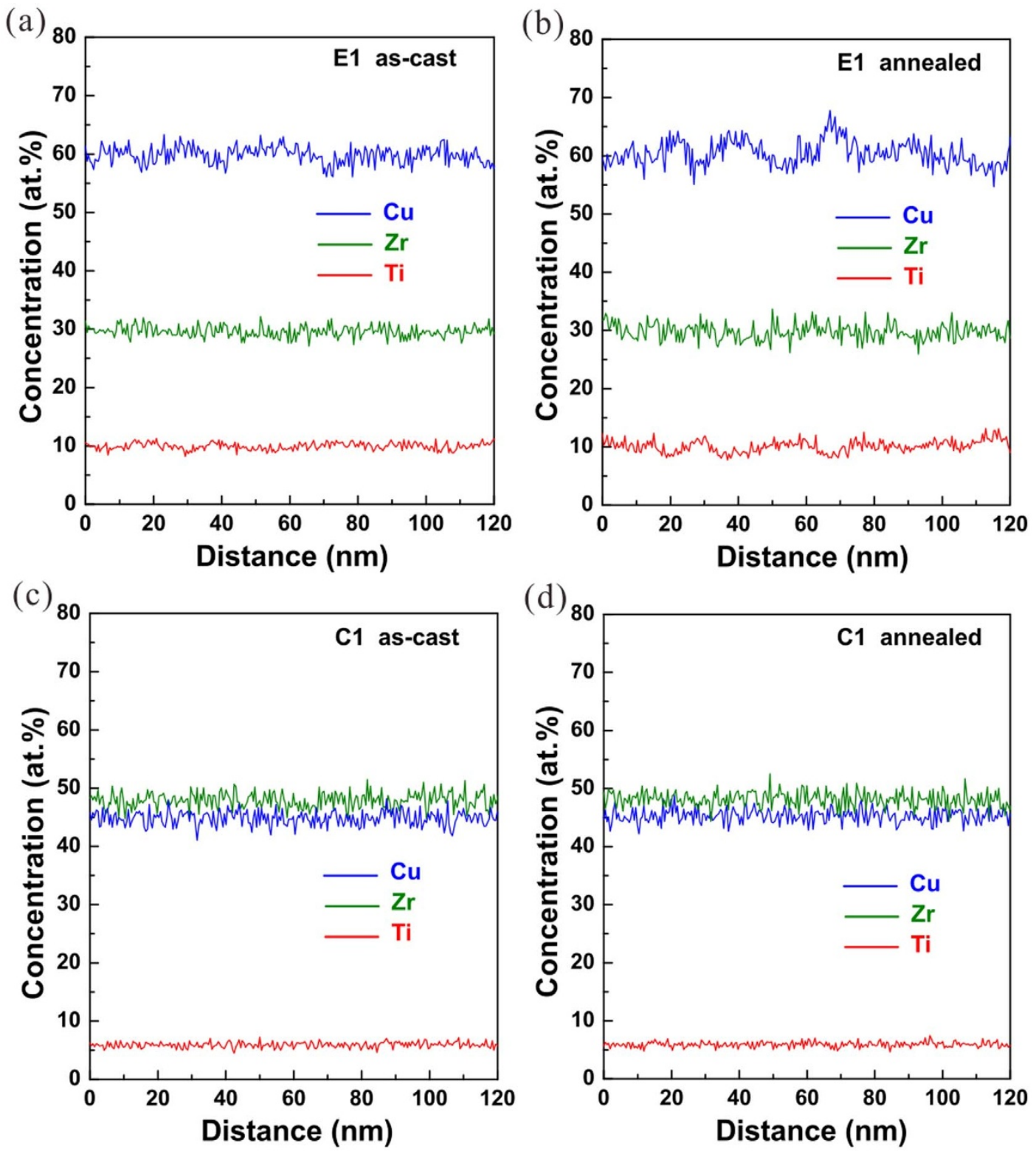

Figure $5 \mid$ Element concentration profiles of the metallic glasses with different composition characteristics and thermal histories. (a) The E1 BMG sample in the as-cast state, (b) The E1 BMG sample annealed at $T_{\mathrm{g}}-20 \mathrm{~K}$ for $3 \mathrm{~h}$, (c) The C1 BMG sample in the as-cast state, and (d) The C1 BMG sample annealed at $T_{\mathrm{g}}-20 \mathrm{~K}$ for $3 \mathrm{~h}$.

which belongs to the same $\mathrm{Cu}-\mathrm{Zr}$-Ti alloy system with different composition characteristics. High-resolution TEM image and selected area electron diffraction pattern reveal that the glassy structures of the tested $\mathrm{E} 1$ and $\mathrm{C} 1$ samples are still preserved after annealing for $3 \mathrm{~h}$ at $T_{\mathrm{g}}-20 \mathrm{~K}$ (see Supplementary Fig. S2). Figure 5a shows the element concentration profiles of the as-cast E1 BMG sample taken from a $2 \mathrm{~mm}$ rod. By eliminating the scattering noise signal, the concentration profiles clearly indicate appreciable fluctuations in the $\mathrm{Cu}$ and $\mathrm{Ti}$ concentrations with the features of enriched $\mathrm{Cu}$ and depleted Ti. Figure $5 \mathrm{~b}$ shows the progress of fluctuation tendency in the $\mathrm{Cu}, \mathrm{Zr}$, and $\mathrm{Ti}$ concentrations for the annealed E1 BMG. This finding provides a direct evidence of uphill diffusion which is related to the spinodal decomposition or phase separation prior to crystallization. On the other hand, no distinct fluctuations are recognized in the concentration profiles of the $\mathrm{Cu}, \mathrm{Zr}$, and $\mathrm{Ti}$ for the as-cast and annealed $\mathrm{C} 1 \mathrm{BMG}$ (Fig. $5 \mathrm{c}$ and $\mathrm{d}$, respectively). Recently, similar results have also been observed in $\mathrm{Cu}_{50} \mathrm{Zr}_{45} \mathrm{Gd}_{5}$ BMG and $\mathrm{Cu}_{50} \mathrm{Zr}_{48} \mathrm{Gd}_{2}$ BMG (near the composition of the $\mathrm{Cu}_{50} \mathrm{Zr}_{50}$ intermetallic compound) with inhomogeneous and homogeneous element distribution features, respectively ${ }^{36}$. All of these results prove that different types of metallic glass have distinctly different element distribution characteristics. It is thus concluded that the distribution state of the constituent elements is inhomogeneous for E-MGs and homogeneous for C-MGs.

\section{Discussion}

In general, the intrinsic mechanical properties of monolithic metallic glasses are controlled by the alloy composition (i.e., the atomic fractions of constituent elements in the alloy) and by the internal atomiclevel "structure", i.e., how the atoms of various species are mixed (including the element distribution characteristics), topologically packed and bonded in the alloys ${ }^{44}$. In contrast with the understanding of the mechanical properties of crystalline metals and alloys, which correlate with the microstructure of the material, the lack of an in-depth description of the topological structures of various multicomponent bulk metallic glasses as well as the inability to conduct 
(a)

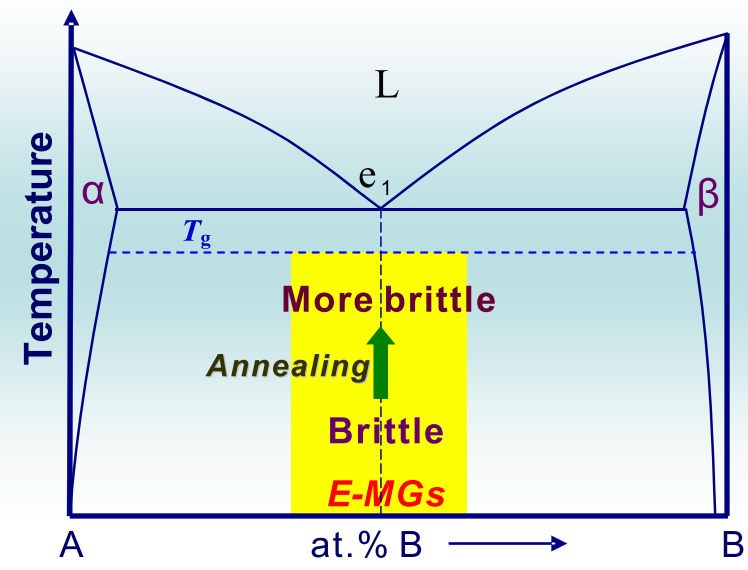

(b)

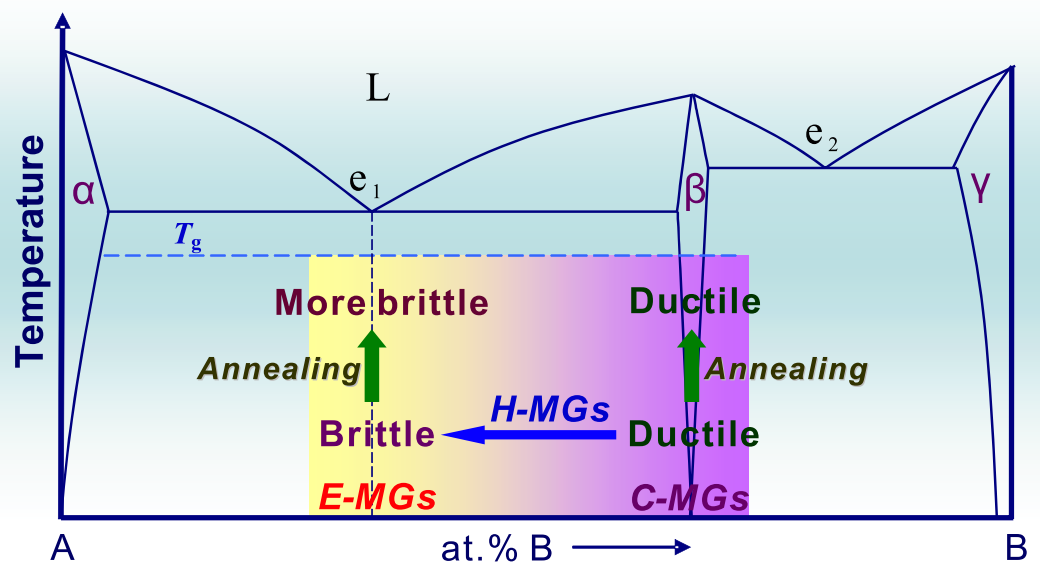

Figure 6 Schematic diagrams (taking binary phase diagrams as examples) illustrating the composition dependence of intrinsic plasticity or brittleness in metallic glasses with different compositions and thermal histories. (a) Glass-forming alloy systems in which any of the intermetallic compound composition has no glass-forming ability and the glass-forming composition regions are just confined around the composition of the eutectics. (b) Glassforming alloy systems in which the glass-forming composition regions can extend from the eutectics to the corresponding intermetallic compounds. The yellow- and purple- regions represent the glass-forming composition regions of E-MGs and C-MGs, respectively. A hybrid-type glass-forming composition region (H-MGs) between E-MGs and C-MGs is also presented.

systematic parametric studies of a multicomponent glassy structure is major impediments for gaining such knowledge about bulk metallic glasses. Here we propose that the investigation of the element distribution characteristics of metallic glasses, as a much easier approach compared with the study of topological structures, may provide us a new viewpoint to understand the intrinsic ductile/brittle behaviour of monolithic bulk metallic glasses with various alloy compositions and different thermal histories. In view that the element distribution characteristics (homogeneous or inhomogeneous) of bulk metallic glasses with different composition features can be well deduced on the basis of the information of phase diagrams, a universal guideline to search for new ductile monolithic bulk metallic glasses in other known and unknown glass-forming alloy systems can be proposed, as illustrated in Figure 6. As for the glass-forming alloy systems in which any of the intermetallic compound composition has no glass-forming ability and the glass-forming composition regions are just confined around the composition of the eutectics, these metallic glasses exhibit obvious brittle characteristics owing to

Table 2 | A summary of some reported Pt-, Pd-, and ZrCu-based BMGs that possess high plasticity. These BMGs have compositions at or close to that of their corresponding compounds, which belong to the C-MGs or H-MGs classification

\begin{tabular}{lllll} 
Alloy system & Compound with GFA & Corresponding C-MG & \multicolumn{2}{c}{ Reported ductile BMG } \\
\hline $\mathrm{Cu}-\mathrm{Zr}$ & $\mathrm{CuZr}$ & $\mathrm{Cu}_{50} \mathrm{Zr}_{50}$ & $\mathrm{Cu}_{50} \mathrm{Zr}_{50}$ & Ref \\
$\mathrm{Pd}-\mathrm{Si}$ & $\mathrm{Pd}_{5} \mathrm{Si}$ & $\mathrm{Pd}_{83.3} \mathrm{Si}_{16.7}$ & $\mathrm{Pd}_{81} \mathrm{Si}_{19}$ & {$[45,46]$} \\
$\mathrm{Pt}-\mathrm{P}$ & $\mathrm{Pt}_{5} \mathrm{P}_{2}$ & $\mathrm{Pt}_{57.5} \mathrm{Cu}_{14.7} \mathrm{Ni}_{5.3} \mathrm{P}_{22.5}$ & {$[45,47]$} \\
$\mathrm{Ni}-\mathrm{Pd}-\mathrm{P}$ & $\mathrm{Ni}_{5} \mathrm{Pd}_{3} \mathrm{P}_{2}$ & $\mathrm{Ni}_{50} \mathrm{Pd}_{30} \mathrm{P}_{20}$ & {$[45,48]$} \\
$\mathrm{Pd}-\mathrm{P}$ & $\mathrm{Pd}_{4.8} \mathrm{P}$ & $\mathrm{Ni}_{50} \mathrm{Pd}_{30} \mathrm{P}_{20}$ & $\mathrm{Pd}_{79} \mathrm{Ag}_{3.5} \mathrm{P}_{6} \mathrm{Si}_{9.5} \mathrm{Ge}_{2}$ & {$[49,50]$} \\
$\mathrm{Pd}-\mathrm{Si}$ & $\mathrm{Pd}_{5} \mathrm{Si}$ & $\mathrm{Pd}_{82.8} \mathrm{P}_{17.2}$ & & \\
$\mathrm{Pd}-\mathrm{Ge}$ & $\mathrm{Pd}_{5} \mathrm{Ge}$ & $\mathrm{Pd}_{83.3} \mathrm{Si}_{16.7}$ & & \\
$\mathrm{Zr}-\mathrm{Cu}-\mathrm{Ni}-\mathrm{Al}$ & $\mathrm{Zr}_{58} \mathrm{Cu}_{15} \mathrm{Ni}_{15} \mathrm{Al}_{12}$ & $\mathrm{Pd}_{83.3} \mathrm{Ge}_{16.7}$ & $\mathrm{Zr}_{64.13} \mathrm{Cu}_{15.75} \mathrm{Ni}_{10.12} \mathrm{Al}_{10}$ & {$[5], \mathrm{This}_{10}$ work } \\
\hline
\end{tabular}


their E-MGs character (Fig. 6a). However, for the glass-forming alloy systems in which the glass-forming composition regions can extend from the eutectics to the corresponding intermetallic compounds, a dramatic composition effect on intrinsic plasticity or brittleness in these glass-forming alloy systems is expected. Specifically, as can be seen in Figure 6b, metallic glasses with compositions at or near intermetallic compounds (C-MGs), in contrast to the ones at or near eutectics (E-MGs), are extremely ductile and also insensitive to annealing-induced embrittlement. In addition, it is also worth noting that there might be a glass-forming composition region which is exactly located at the region between the E-MGs-forming region and the C-MGs-forming region. Metallic glasses in this composition region are represented as hybrid-type metallic glasses (H-MGs), which is also much ductile than typical E-MGs, as illustrated in Figure 6b.

To further confirm this universal point, Table 2 summarizes typical highly ductile BMGs that have been previously studied up to date $^{5,45-51}$. All of the BMGs listed here have compositions at or near that of their corresponding intermetallic compounds, which belong to the C-MGs or at least belong to the H-MGs classification. In contrast, although bearing high Poisson's ratios (larger than 0.4), Au-based BMGs exhibit brittle characteristics owing to their EMGs character, which is related to a eutectic reaction of $L \rightarrow \mathrm{Au}$ $+\mathrm{Si}^{11,45}$. In addition, the well-known brittleness of the $\mathrm{Mg}$-based and Fe-based BMGs can also be well understood by their E-MGs characters. For example, brittle Mg-Cu-RE (RE $=\mathrm{Gd}$ or $\mathrm{Y}) \mathrm{BMGs}^{52,53}$, $\mathrm{Mg}-\mathrm{Zn}-\mathrm{Ca} \mathrm{BMGs}^{54}$, and Fe-B-based $\mathrm{BMGs}^{55,56}$ are related to the eutectic reactions of $\mathrm{L} \rightarrow \mathrm{Mg}_{2} \mathrm{Cu}+\mathrm{Mg}_{3} \mathrm{CuRE}^{57,58}, \mathrm{~L} \rightarrow \mathrm{Mg}+$ $\mathrm{Ca}_{2} \mathrm{Mg}_{5} \mathrm{Zn}_{13}{ }^{59,60}$, and $\mathrm{L} \rightarrow \mathrm{Fe}+\mathrm{Fe}_{2} \mathrm{~B}^{45}$, respectively. These results are consistent with the guideline proposed in Figure $6 \mathrm{a}$.

In conclusion, we have confirmed the universal correlation between intrinsic plasticity or brittleness and element distribution characteristics of E-MGs and C-MGs in both as-cast and annealed states. Our work discovers that the composition dependence of plasticity or brittleness in BMGs in various thermal history states can be well understood by the new concept of E-MGs and C-MGs classification. It is particularly noticed that the C-MGs which possess a homogenous element distribution state are ductile and have an extremely high resistance to annealing-induced embrittlement. This finding will greatly enhance the application potential of the C-MGs as structural materials, even in the case where thermal treatment is unavoidable. Moreover, we proposed a new interpretation that the physical and chemical origins for the appearances of ductile C-MGs and brittle E-MGs with various thermal history states are closely related to the element distribution features of the metallic glasses, being inconsistent with the previous empirical rules or common concepts, which correlate the ductile/brittle behaviour of metallic glasses with Poisson's ratio or free volume change, etc. Based on this view of point, we have revealed a close correlation between the element distribution characteristics and the plasticity of metallic glasses, which has significant implications on understanding the intrinsic ductile/brittle behaviour of metallic glasses with wide ranges of compositions and thermal histories. The present discovery also provides useful and universal guidelines, based on the information of phase diagrams, to aid in searching for new ductile bulk metallic glasses at or near the intermetallic compound compositions in other known and unknown glass-forming alloy systems.

\section{Methods}

Ternary $\mathrm{Cu}_{60} \mathrm{Zr}_{30} \mathrm{Ti}_{10}, \mathrm{Cu}_{49} \mathrm{Hf}_{42} \mathrm{Al}_{9}, \mathrm{Cu}_{47} \mathrm{Zr}_{47} \mathrm{Ti}_{6}$, and $\mathrm{Cu}_{44} \mathrm{Zr}_{52} \mathrm{Al}_{4}$ alloys and quaternary $\mathrm{Zr}_{58} \mathrm{Cu}_{15} \mathrm{Ni}_{15} \mathrm{Al}_{12}$ alloy were chosen in the present study. The master alloys were prepared by arc melting a mixture of pure elements under an Ar atmosphere. Rods of 2-2.5 $\mathrm{mm}$ in diameter and plates of $1 \mathrm{~mm}$ in thickness and $8 \mathrm{~mm}$ in width were produced by copper mould suction casting. Some of the as-cast samples were isothermally annealed for $3 \mathrm{~h}$ at $T_{\mathrm{g}}-20 \mathrm{~K}$. The amorphous nature and the thermal parameters of the $2.5 \mathrm{~mm}$ rods were ascertained by X-ray diffraction (XRD) and optical microscope. The glass transition temperature, the onset temperature of melting, and the liquidus temperature of the alloys were investigated by differential scanning calorimetry (DSC) at a heating rate of $20 \mathrm{~K} / \mathrm{min}$. Samples with a gauge aspect ratio of $2: 1$ were cut from $2 \mathrm{~mm}$ rods for uniaxial compression testing with a strain rate of $4 \times 10^{-4} \mathrm{~s}^{-1}$. Samples with dimensions of $\sim 0.9 \times 1.2 \times 18 \mathrm{~mm}^{3}$ were cut from the as-cast and annealed plates and tested using a homemade bending apparatus. The mandrel radius and the span of the bending apparatus are $5 \mathrm{~mm}$ and $13 \mathrm{~mm}$, respectively. The density of the as-cast and annealed samples was measured using the Archimedes method in purified water at room temperature. The effective resolution for the density measurement is $\pm 0.0005 \mathrm{~g} / \mathrm{cm}^{3}$. The same bulk samples, with an approximate weight of $3 \mathrm{~g}$, were used to measure the density before and after annealing. A micro-hardness test was performed using a Mitutoyo MVK-H3 hardness tester with a $1 \mathrm{~kg}$ load and a $10 \mathrm{~s}$ loading time. The micro-hardness was obtained from the average of 10 individual measurements. To obtain near-equilibrium solidification microstructures of the alloys, sealed quartz tubes containing molten master alloys were cooled from $1273 \mathrm{~K}$ to $1023 \mathrm{~K}$ at a cooling rate of $1 \mathrm{~K} / \mathrm{min}$, followed by quenching into water from $1023 \mathrm{~K}$. The near-equilibrium solidification microstructures of the master alloys and the deformation and fracture features of the BMG samples were observed with a scanning electron microscope (SEM). The local compositions of the constituent phases in the near-equilibrium solidification microstructures were determined using an energy-dispersive X-ray spectrometer (EDS) attached to the SEM. A dual-focus ion beam system (SII 3050MS) was used for the fabrication of the transmission electron microscopy (TEM) samples from the $2 \mathrm{~mm}$ metallic glass rods. The TEM observations were performed using a JEOL JEM2100F microscope operating at $200 \mathrm{kV}$. The element concentration profiles of the samples were obtained using an EDS attached to the TEM.

1. Inoue, A. Stabilization of metallic supercooled liquid and bulk amorphous alloys. Acta Mater. 48, 279-306 (2000)

2. Ashby, M. F. \& Greer, A. L. Metallic glasses as structural materials. Scripta Mater. 54, 321-326 (2006)

3. Schuh, C. A., Hufnagel, T. C. \& Ramamurty, U. Mechanical behavior of amorphous alloys. Acta Mater. 55, 4067-4109 (2007).

4. Conner, R. D. \& Johnson, W. L. Composition dependent ductility in the amorphous Zr-Ti-Ni-Cu-Be alloy system. Scripta Mater. 55, 645-648 (2006).

5. Liu, Y. H. et al. Super plastic bulk metallic glasses at room temperature. Science. 315, 1385-1388 (2007).

6. Xu, J., Ramamurty, U. \& Ma, E. The fracture toughness of bulk metallic glasses. JOM. 62, 10-18 (2010).

7. Kumar, G., Prades-Rodel, S., Blatter, A. \& Schroers, J. Unusual brittle behavior of Pd-based bulk metallic glass. Scripta Mater. 65, 585-587 (2011).

8. Schroers, J. \& Johnson, W. L. Ductile bulk metallic glass. Phys. Rev. Lett. 93, 255506 (2004)

9. Lewandowski, J. J., Wang, W. H. \& Greer, A. L. Intrinsic plasticity or brittleness of metallic glasses. Phil. Mag. Lett. 85, 77-87 (2005).

10. Zheng, Q., Ma, H., Ma, E. \& Xu, J. Mg-Cu-(Y,Nd) pseudo-ternary bulk metallic glasses: The effects of Nd on glass-forming ability and plasticity. Scripta Mater. 55, 541-544 (2006)

11. Guo, H. et al. Effect of Au content on thermal stability and mechanical properties of Au-Cu-Ag-Si bulk metallic glasses. Metall. Mater. Trans. A. 42, 1486-1490 (2011).

12. Wu, T. W. \& Spaepen, F. The relation between embrittlement and structural relaxation of an amorphous metal. Philos. Mag. B. 61, 739-750 (1990).

13. Lewandowski, J. J. Effects of annealing and changes in stress state on fracture toughness of bulk metallic glass. Mater. Trans. 42, 633-637 (2001).

14. Spaepen, F. A microscopic mechanism for steady state inhomogeneous flow in metallic glasses. Acta Metall 25, 407-415 (1977).

15. Egami, T. Understanding the properties and structure of metallic glasses at the atomic level. JOM. 62, 70-75 (2010).

16. Turnbull, D. Under what conditions can a glass be formed? Contemp. Phys. 10 , 473-488 (1969)

17. Wu, W. F. \& Li, Y. Bulk metallic glass formation near intermetallic composition through liquid quenching. Appl. Phys. Lett. 95, 011906 (2009).

18. Tang, M. B., Zhao, D. Q., Pan, M. X. \& Wang, W. H. Binary Cu-Zr bulk metallic glasses. Chin. Phys. Lett. 21, 901-903 (2004).

19. Dai, C. L., Deng, J. W., Zhang, Z. X. \& Xu, J. Cu-Zr-Ti ternary bulk metallic glasses correlated with $\left(\mathrm{L} \rightarrow \mathrm{Cu}_{8} \mathrm{Zr}_{3}+\mathrm{Cu}_{10} \mathrm{Zr}_{7}\right)$ univariant eutectic reaction. J. Mater. Res. 23, 1249-1257 (2008).

20. Jia, P. \& Xu, J. Comparison of bulk metallic glass formation between Cu-Hf binary and $\mathrm{Cu}-\mathrm{Hf}-\mathrm{Al}$ ternary alloys. J. Mater. Res. 24, 96-106 (2009).

21. Villars, P., Prince, A. \& Okamoto, H. Handbook of Ternary Alloy Phase Diagrams. (ASM International, Materials Park, OH, 1995).

22. Stillinger, F. H. A topographic view of supercooled liquids and glass formation. Science. 267, 1935-1939 (1995).

23. Malandro, D. L. \& Lacks, D. J. Relationships of shear-induced changes in the potential energy landscape to the mechanical properties of ductile glasses. J. Chem. Phys. 110, 4593-4601 (1999).

24. Johnson, W. L., Demetriou, M. D., Harmon, J. S., Lind, M. L. \& Samwer, K. Rheology and ultrasonic properties of metallic glass-forming liquids: A potential energy landscape perspective. MRS. Bull. 32, 644-650 (2007).

25. Johnson, W. L. \& Samwer, K. A universal criterion for plastic yielding of metallic glasses with a $\left(\mathrm{T} / \mathrm{T}_{\mathrm{g}}\right)^{2 / 3}$ temperature dependence. Phys. Rev. Lett. 95, 195501 (2005). 
26. Scudino, S. et al. Ductile bulk metallic glasses produced through designed heterogeneities. Scripta Mater. 65, 815-818 (2011).

27. Goodwin, J. W. \& Hughes, R. W. Rheology for Chemists: An Introduction. (The Royal Society of Chemistry. Cambridge, 2000).

28. Malandro, D. L. \& Lacks, D. J. Molecular-level mechanical instabilities and enhanced self-diffusion in flowing liquids. Phys. Rev. Lett. 81, 5576-5579 (1998).

29. Hilliard, J. E. Spinodal decomposition. Phase Transformations. (American Society for Metals, Metals Park, Ohio, 1970).

30. Gunton, J. D., Miguel, M. S. \& Sahni, P. S. Phase Transitions and Critical Phenomena. (Academic Press, London, 1983).

31. Mattern, N. et al. Spinodal decomposition of Ni-Nb-Y metallic glasses. Acta Mater. 57, 903-908 (2009).

32. Busch, R., Schneider, S., Peker, A. \& Johnson, W. L. Decomposition and primary crystallization in undercooled $\mathrm{Zr}_{41.2} \mathrm{Ti}_{13.8} \mathrm{Cu}_{12.5} \mathrm{Ni}_{10.0} \mathrm{Be}_{22.5}$ melts. Appl. Phys. Lett. 67, 1544-1546 (1995)

33. Miller, M. K., Larson, D. J., Schwarz, R. B. \& He, Y. Decomposition in $\mathrm{Pd}_{40} \mathrm{Ni}_{40} \mathrm{P}_{20}$ metallic glass. Mater. Sci. Eng., A 250, 141-145 (1998).

34. Oh, J. C., Ohkubo, T., Kim, Y. C., Fleury, E. \& Hono, K. Phase separation in $\mathrm{Cu}_{43} \mathrm{Zr}_{43} \mathrm{Al}_{7} \mathrm{Ag}_{7}$ bulk metallic glass. Scripta Mater. 53, 165-169 (2005).

35. Mattern, N. et al. Phase separation in $\mathrm{Cu}_{46} \mathrm{Zr}_{47-\mathrm{x}} \mathrm{Al}_{7} \mathrm{Gd}_{\mathrm{x}}$ metallic glasses. J. Alloys Compd. 509S, S23-S26 (2011).

36. Mattern, N., Shariq, A., Schwarz, B., Vainio, U. \& Eckert, J. Structural and magnetic nanoclusters in $\mathrm{Cu}_{50} \mathrm{Zr}_{50-\mathrm{x}} \mathrm{Gd}_{\mathrm{x}}(\mathrm{x}=5$ at.\%) metallic glasses. Acta Mater. 60, 1946-1956 (2012).

37. Shariq, A. \& Mattern, N. A study of phase separated $\mathrm{Ni}_{66} \mathrm{Nb}_{17} \mathrm{Y}_{17}$ metallic glass using atom probe tomography. Ultramicroscopy. 111, 1370-1374 (2011).

38. Kim, D. H., Kim, W. T., Park, E. S., Mattern, N. \& Eckert, J. Phase separation in metallic glasses. Prog. Mater Sci. 58, 1103-1172 (2013).

39. Song, S. X., Bei, H., Wadsworth, J. \& Nieh, T. G. Flow serration in a Zr-based bulk metallic glass in compression at low strain rates. Intemetallics. 16, 813-818 (2008).

40. Zhang, Y. \& Greer, A. L. Thickness of shear bands in metallic glasses. Appl. Phys. Lett. 89, 071907 (2006).

41. Song, S. X. \& Nieh, T. G. Direct measurements of shear band propagation in metallic glasses - An overview. Intemetallics. 19, 1968-1977 (2011).

42. Guan, P. F., Chen, M. W. \& Egami, T. Stress-temperature scaling for steady-state flow in metallic glasses. Phys. Rev. Lett. 104, 205701 (2010).

43. Liu, Z. Y., Yang, Y. \& Liu, C. T. Yielding and shear banding of metallic glasses. Acta Mater. 61, 5928-5936 (2013)

44. Cheng, Y. Q., Cao, A. J. \& Ma, E. Correlation between the elastic modulus and the intrinsic plastic behavior of metallic glasses: The roles of atomic configuration and alloy composition. Acta Mater. 57, 3253-3267 (2009).

45. Massalski, T. B. et al. Binary Alloy Phase Diagrams. (American Society for Metals, Metals Park, Ohio, 1986).

46. Inoue, A., Zhang, W., Tsurui, T., Yavari, A. R. \& Greer, A. L. Unusual roomtemperature compressive plasticity in nanocrystal-toughened bulk copperzirconium glass. Phil. Mag. Lett. 85, 221-229 (2005).

47. Yao, K. F., Ruan, F., Yang, Y. Q. \& Chen, N. Superductile bulk metallic glass. Appl. Phys. Lett. 88, 122106 (2006)

48. Schroers, J. \& Johnson, W. L. Ductile bulk metallic glass. Phys. Rev. Lett. 93, 255506 (2004)

49. Donovan, P. E., Evans, P. V. \& Greer, A. L. Ternary compound in the Pd-Ni-P alloy system. J. Mater. Sci. Lett. 5, 951-952 (1986).

50. Wang, K. et al. Micromechanisms of serrated flow in a $\mathrm{Ni}_{50} \mathrm{Pd}_{30} \mathrm{P}_{20}$ bulk metallic glass with a large compression plasticity. Acta Mater. 56, 2834-2842 (2008).

51. Demetriou, M. D. et al. A damage-tolerant glass. Nat. Mater. 10, 123-128 (2011),

52. Chen, G. \& Ferry, M. Some aspects of the fracture behaviour of $\mathrm{Mg}_{65} \mathrm{Cu}_{25} \mathrm{Y}_{10}$ bulk metallic glass during room-temperature bending. J. Mater. Sci. 41, 4643-4648 (2006)
53. Zheng, Q., Cheng, S., Strader, J. H., Ma, E. \& Xu, J. Critical size and strength of the best bulk metallic glass former in the Mg-Cu-Gd ternary system. Scripta Mater. 56, 161-164 (2007)

54. Zhao, Y. Y., Ma, E. \& Xu, J. Reliability of compressive fracture strength of Mg-ZnCa bulk metallic glasses: Flaw sensitivity and Weibull statistics. Scripta Mater. 58, 496-499 (2008).

55. Inoue, A., Shen, B. L. \& Chang, C. T. Super-high strength of over $4000 \mathrm{MPa}$ for Febased bulk glassy alloys in $\left[\left(\mathrm{Fe}_{1-\mathrm{x}} \mathrm{Co}_{\mathrm{x}}\right)_{0.75} \mathrm{~B}_{0.2} \mathrm{Si}_{0.05}\right]_{96} \mathrm{Nb}_{4}$ system. Acta Mater. 52, 4093-4099 (2004).

56. Song, D. S., Kim, J.-H., Fleury, E., Kim, W. T. \& Kim, D. H. Synthesis of ferromagnetic Fe-based bulk glassy alloys in the Fe-Nb-B-Y system. J. Alloys Compd. 389, 159-164 (2005).

57. Satta, M., Palumbo, M., Rizzi, P. \& Baricco, M. Ternary compounds and glass formation in the Cu-Mg-Y system. Adv. Eng. Mater. 9, 475-479 (2007).

58. Zheng, Q. Mg-Cu(Ag)-Gd Bulk metallic glass forming alloy: Phase selection of melt crystallization. Sci. Adv. Mater. 4, 969-977 (2012).

59. Clark, J. B. The solid constitution in Magnesium-rich region of the Mg-Ca-Zn phase diagram. Trans. AIME. 221, 644-645 (1961).

60. Zhao, Y. Y. \& Zhao, X. Structural relaxation and its influence on the elastic properties and notch toughness of Mg-Zn-Ca bulk metallic glass. J. Alloys Compd. 515, 154-160 (2012).

\section{Acknowledgments}

This work is supported by the Zhejiang Provincial Natural Science Foundation of China (Grant no. Q12E010015), the Ningbo Municipal Nature Science Foundation (Grant no. 2012A610103), and the National Natural Science Foundation of China (Grant no. 51271194). We thank S. Y. Ma from Institute of Metal Research, Chinese Academic of Sciences, and D. Estévez from Ningbo Institute of Materials Technology and Engineering, Chinese Academy of Sciences for their assistance in this work.

\section{Author contributions}

R.W.L. and B.L.S. designed the project. Y.Y.Z. and C.T.C. designed and carried out the experiments. Y.Y.Z. proposed the deformation model. Y.Y.Z. and A.I. wrote the manuscript. R.W.L., B.L.S., A.I., Y.Y.Z., C.T.C., J.L. and X.M.W. contributed to the discussion of the results.

\section{Additional information}

Supplementary information accompanies this paper at http://www.nature.com/ scientificreports

Competing financial interests: The authors declare no competing financial interests. How to cite this article: Zhao, Y.-Y. et al. Composition Effect on Intrinsic Plasticity or Brittleness in Metallic Glasses. Sci. Rep. 4, 5733; DOI:10.1038/srep05733 (2014).

This work is licensed under a Creative Commons Attribution-NonCommercialNoDerivs 4.0 International License. The images or other third party material in this article are included in the article's Creative Commons license, unless indicated otherwise in the credit line; if the material is not included under the Creative Commons license, users will need to obtain permission from the license holder in order to reproduce the material. To view a copy of this license, visit http:// creativecommons.org/licenses/by-nc-nd/4.0/ 